Two of the questions I asked myself while the patient was under my care, were: Was there a time when surgical interference might bave prevented the general eruption of the disease along the genito-urinary tract? There was an interval of several months after the appearance of the nodules in the epididymes before ur:nary symptoms came on. An excision of these nodules might have prevented further progress, and should always, I think, be urged at an early period, when they cannot be definitely traced to a venereal or traumatic source. The second question is : Could any operation have been performed for the relief of the patient's sufferings after the disease was well established?

In another case which presented such suffering as this patient had, I should certainly advise the suprapubic opening of the blalder and the stretching of the vesical neck, in the hope of affording relief to pain. The perineal opening which I made in this patient did not relieve pain. It is interesting in this connection to note two cases of Professor Guyon's, published in the Revue de Chirurgie, April 10, 1888, page 314, in which he recommends that the high cut be performed in cases where the disease be limited to the bladder only, with a view to radical cure. It will be doubted by some if the disease ever occurs in this limited form.

His first case was that of a young man of twentyfour years. Cystitis for eighteen months, great pain, tubercle bacilli in the urine. Supra-pubic opening of the bladder, and swabbing out of the bladder with saturated iodoform oil, drainage. The tubes were removed on the seventeenth day. Forty-five days later pain was greatly diminished. Two years and a-half later patient was in excellent health, and the urine was clear, free from pus and bacilli.

Second case. Man of forty years. Vesical pain for four months. Numerous bacilli. Palliative treatment for four months. Had no effect. Operation as before. Curretted the inner surface of the bladder, and touched it with cautery. Tubes removed on the fifteenth day. Bacilli disappeared six months later. This patient, however, has still a cystitis.

\section{A METHOD OF DETERMINING THE ANGLE OF FLEXION OF THE DISEASED LEG IN HIP DISEASE:}

BY GEORGE L. KINGSLEY, A.B., HARVARD MEDICAL SCHOOL.

THE estimation of the amount of flexion of the leg upon the pelvis, in the acute stage of hip-disease, is of much importance as a matter of record and as an indication of the progress of the case. The estination of this angle is commonly made by the use of the goniometer. As one seldom has this instrument at hand, and as its use is attended with many disadvantages, the following method is offered:

The object of this article is to furnish a ready and accurate method of estimating with a common tapemeasure the angle of flexion of the leg, and is intended to be supplementary to the article by Dr. Lovett, ${ }^{1}$ on the estimation of adduction and abduction by a similar method. Lay the patient on his back on a table or any flat surface; and then raise the diseased leg by the heel until the lumbar vertebræ touch the table; this

1 Boston Med. and Surg. Journ., March 8, 1888. shows that the pelvis is in the normal position and the angle which the leg makes with the table, the angle

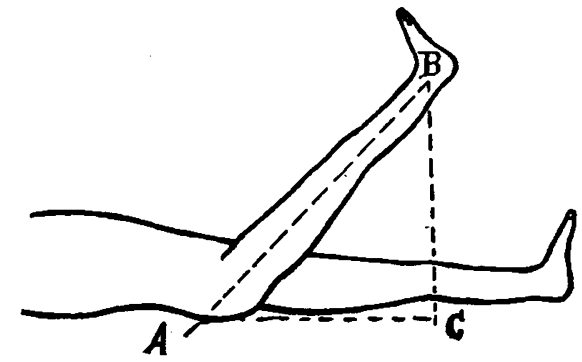

C A B, is the angle of flexion of the thigh, from the normal position. It is this angle which it is desired to measure. Having placed the clild in this position, measure off two feet on the external aspect of the leg with a tape measure with the zero of the tape on the table at (A), and note the point (B), from here measure the perpendicular distance in inches to the table (C), consult 'Table I and opposite the number of inches found by measuring $\mathrm{BC}$, will be found the number of degrees representing the flexion of the diseased leg from the normal position.

Now we have a right-angled triangle A B C, of which the sides A B ( 24 inches) and B C (by measurement) are known. $\frac{B C}{A B}=$ sine $B A C$ (the angle of flexion), or $B C=A$ B sine $B$ A C. Therefore, if we compute by this formula a table which shall give the angles corresponding to the various lengths of $B \mathbf{C}$, having measured this perpendicular distance $(B \mathrm{C})$ we can by glancing down the table until we find the number corresponding to the distance measured, ascertain the number of degrees in the desired angle.

\begin{tabular}{|c|c|c|c|c|c|c|c|}
\hline In & Dea. & $I n$ & Dea & $I n$ & Ded & In & $D e a$ \\
\hline .5 & 1 & 6.5 & 16 & $12 . \check{0}$ & 31 & 18.5 & 50 \\
\hline 1.0 & 2 & 7.0 & 17 & 13.0 & 33 & 19.0 & 52 \\
\hline 1.5 & 3 & 7.5 & 19 & $13 . \delta$ & 34 & 19.5 & 54 \\
\hline $\begin{array}{l}2.0 \\
2.5\end{array}$ & $\begin{array}{l}4 \\
6\end{array}$ & $\begin{array}{l}8.0 \\
8.5\end{array}$ & $\begin{array}{l}20 \\
21\end{array}$ & $\begin{array}{l}14.0 \\
14.5\end{array}$ & $\begin{array}{l}36 \\
37\end{array}$ & $\begin{array}{l}20.0 \\
20.5\end{array}$ & $\begin{array}{l}56 \\
58\end{array}$ \\
\hline 3.0 & 7 & $\mathbf{9 . 0}$ & 22 & 15.0 & 39 & 21.0 & 60 \\
\hline 3.5 & $\dot{9}$ & 9.5 & 24 & 15.5 & 40 & 21.5 & 63 \\
\hline 4.0 & 10 & 10.0 & 25 & 16.0 & 42 & 22.0 & 67 \\
\hline 4.5 & 11 & 10.5 & 27 & 16.5 & $\$ 3$ & 22.5 & 70 \\
\hline 5. & 12 & 11.0 & 28 & 17.0 & 45 & 23.0 & 75 \\
\hline 5.5 & 14 & 11.5 & 29 & 17.5 & 47 & 23.5 & 80 \\
\hline & 15 & 12.0 & 30 & 18.0 & 48 & 24.0 & 90 \\
\hline
\end{tabular}

If the leg is so short that it is impracticable to measure off twenty-four inches we can measure to a point on the leg distant twelve inches from the table; ascertain the distance to the table in a perpendicular line just as before, double this distance and look in the table as before.

\section{REPOR'L ON PROGRESS IN DERMATOLOGY.}

BY G. H. TILDEN, M.D.,

Physician to City Hospital, Department of Diseases of the Shin: Instructor in the Boston Polyclinic.

\section{TREATMENT OF LUPLS ERYTHEMATOSCS. 1}

The treatment of this disease being an uncertain and of ten thankless task, the following lecture upon the subject by an eminent authority is of interest. The treatment of lupus erythematosus is essentially different both in ways and means, from that of lupus vulgaris. In the case of lupus vulgaris it is possible by chemical ot mechanical means to destroy and get rid of the pathological infiltration which constitutes the disease. When this has been done aud the loss of 